\title{
CASE REVIEW
}

\section{Ptosis that resolves with application of an ice pack}

\author{
Arup Chakraborty consultant general medicine and intensive care ${ }^{1}$, John Jacob consultant neurology $^{1}$ \\ 2
}

${ }^{1}$ Milton Keynes University Hospital, Milton Keynes, UK; ${ }^{2}$ Nuffield Department of Clinical Neurosciences, University of Oxford, Oxford, UK

\begin{abstract}
A man in his 50s presented with a one week history of left sided ptosis and difficulty swallowing. The ptosis was absent on waking, worsened during the day, and improved after rest. His medical history included hypertension. Apart from bilateral ptosis that was worse on the left (fig 1), clinical examination was unremarkable. Application of an ice pack to the left eye for five minutes led to improvement of the ptosis on that side. The ptosis recurred 20-30 minutes after the ice pack was removed.
\end{abstract}
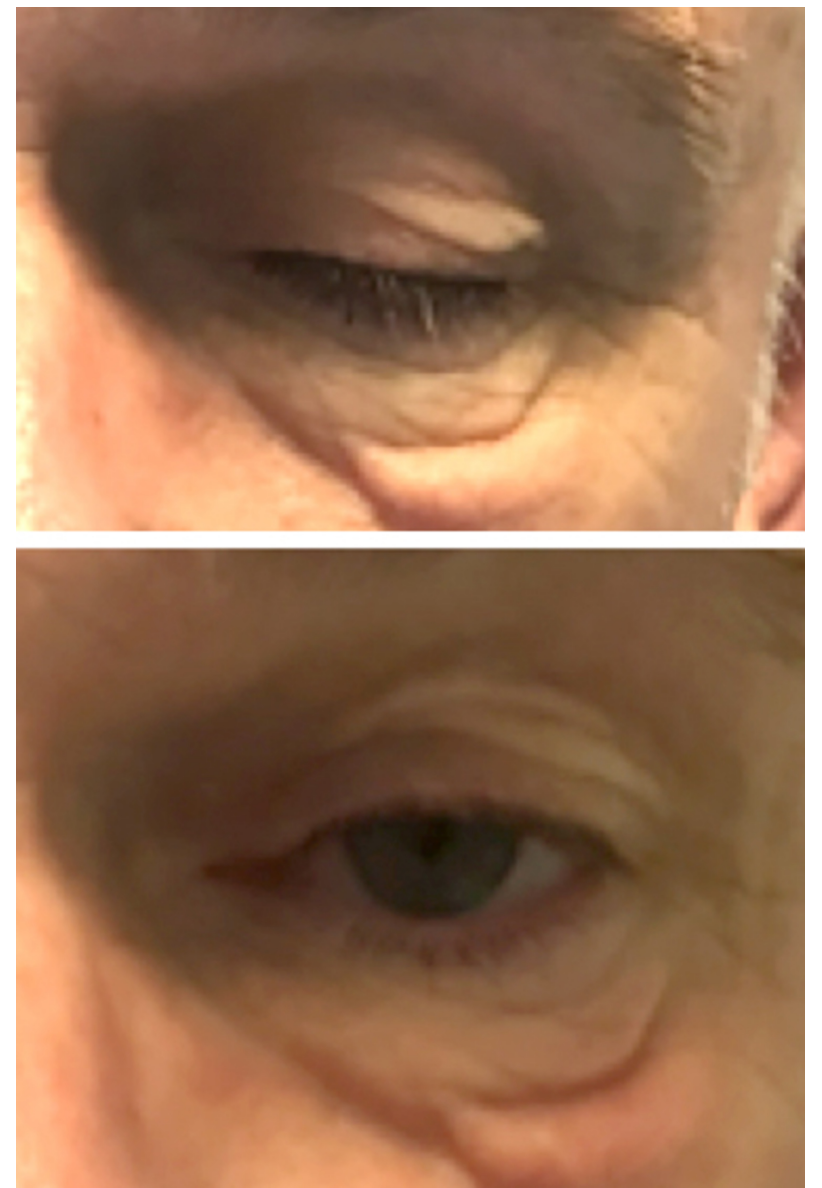

Patient on presentation and after application of ice pack

Within two weeks of the initial presentation, the patient started to experience difficulty chewing, dysphagia for food and saliva, dysarthria, fatigue, and generalised proximal weakness. 
Anti-acetylcholine receptor (anti AChR) autoantibody titre was noticeably increased, at $581 \times 10^{-10} \mathrm{~mol} / \mathrm{L}$ (normal range $0-5 \times 10^{-10}$ $\mathrm{mol} / \mathrm{L})$.

Single fibre electromyography showed increased jitter of the left orbicularis oculi muscle, and repetitive nerve stimulation showed reduced compound muscle action potential of the nasalis muscle.

\section{Question}

What is the most likely underlying diagnosis?

\section{Answer}

Generalised myasthenia gravis.

Most patients have unilateral eye involvement, but the condition can present bilaterally.

Diagnosis is confirmed by raised anti-AChR autoantibody titres, reduced compound muscle action potential on repetitive nerve stimulation, and increased jitter on single fibre electromyography.

Myasthenia gravis has localised and generalised forms:

- Ocular myasthenia gravis: ptosis and diplopia only.

- Oculo-bulbar myasthenia gravis: episodes of respiratory involvement with ptosis and diplopia.

- Generalised myasthenia gravis: generalised proximal weakness; in $85 \%$ of cases it is associated with anti-AChR antibodies.

Ptosis that is absent on waking, worsens as the day progresses, and improves with rest corresponds with the typical pattern of fatigability of all forms of myasthenia gravis. The ice pack test is positive in most patients who have ptosis caused by myasthenia gravis - sensitivity is $77-100 \%$ and specificity is $88-100 \%$, implying a $0-12 \%$ chance that the result will also be positive in patients with non-myasthenic ptosis. ${ }^{1-8}$

In myasthenia gravis with ocular manifestations, cooling is believed to reduce acetylcholinesterase activity by making more acetylcholine available at the neuromuscular junction thereby reversing the ptosis (in non-myasthenic ptosis there is no acetylcholine deficiency at the neuromuscular junction).

Ten per cent of patients who test positive for anti-AChR antibodies will have thymoma. ${ }^{1}$

Causes of unilateral non-myasthenic ptosis include Horner's syndrome, oculomotor nerve palsy, and levator aponeurosis dehiscence (unilateral ptosis). Causes of bilateral non-myasthenic ptosis include myotonic dystrophy and oculopharyngeal muscular dystrophy.

\section{Patient outcome}

The patient underwent computed tomography of the chest, which did not show thymoma. He was successfully treated with pyridostigmine and prednisolone.

\section{Learning points}

- Marked fatigability is characteristic of all forms of myasthenia gravis.

- At presentation, most patients with ocular or generalised myasthenia gravis or both have asymmetrical involvement of the eyes

- If a patient presents with ptosis, consider the ice pack test.

Competing interests: The BMJ has judged that there are no disqualifying financial ties to commercial companies. The authors declare the following other interests: none.

Further details of The BMJ policy on financial interests are here: https://www.bmj. com/about-bmj/resources-authors/forms-policies-and-checklists/declarationcompeting-interests

Patient consent obtained.

Provenance and peer review: not commissioned; externally peer reviewed.

1 Hilton-Jones D. Diagnose myasthenia gravis. Pract Neurol 2002;3:173-710.1046/j.1474-7766.2002.05056.x.

2 Tabassi A, Dehghani A, Saberi B. The ice test for diagnosing myasthenia gravis. Acta Med Iran 2005;43:2

3 Natarajan B, Saifudheen K, Gafoor VA, Jose J. Accuracy of the ice test in the diagnosis of myasthenic ptosis. Neurol India 2016;64:1169-72. 10.4103/0028-3886.193780 27841180

4 Larner AJ, Thomas DJ. Can myasthenia gravis be diagnosed with the 'ice pack test'? A cautionary note. Postgrad Med J 2000;76:162-3. 10.1136/pmj.76.893.162 10684328

5 Kearsey C, Fernando P, D'Costa D, Ferdinand P. The use of the ice pack test in myasthenia gravis. JRSM Short Rep 2010;1:14. 10.1258/shorts.2009.090037 21103106

6 Ramirez-Antunez ÁG, García-Ramos G, Estañol-Vidal B, Juárez-Flores A. Validation of the ice pack test in ophthalmoparesis due to myasthenia gravis. Rev Neurol 2013;57:385-95.24150950

7 Chatzistefanou KI, Kouris T, lliakis E, etal . The ice pack test in the differential diagnosis of myasthenic diplopia. Ophthalmology 2009;116:2236-43. 10.1016/.ophtha.2009.04.039 19744729

8 Ertaş M, Araç N, Kumral K, Tunçbay T. Ice test as a simple diagnostic aid for myasthenia gravis. Acta Neurol Scand 1994;89:227-9. 10.1111/j.1600-0404.1994.tb01667.x 8030407 Published by the BMJ Publishing Group Limited. For permission to use (where not already granted under a licence) please go to http://group.bmj.com/group/rights-licensing/ permissions 